\title{
Emerging roles for IL- 15 in the activation and function of T-cells during immune stimulation
}

This article was published in the following Dove Press journal:

Research and Reports in Biology

25 February 2015

Number of times this article has been viewed

\author{
Scott M Anthony \\ Kimberly S Schluns \\ Immunology Graduate Program, The \\ University of Texas Graduate School \\ of Biomedical Sciences at Houston, \\ Department of Immunology, The \\ University of Texas MD Anderson \\ Cancer Center, Houston, TX, USA
}

Correspondence: Kimberly S Schluns Department of Immunology, M/C 902, University of Texas MD Anderson Cancer Center, PO Box 30I429,

Houston, TX 77030, USA

Tel +l 7I35633303

Fax +I 7I3 5633357

Email kschluns@mdanderson.org
Abstract: Interleukin (IL)-15 is a cytokine that promotes the development and homeostasis of a group of lymphocytes; however, IL-15 is also significantly upregulated in response to pathogen infections and in autoimmune diseases. With its ability to promote T-cell proliferation and survival and influence migration and effector functions, elevated IL-15 can impact T-cell responses in numerous ways. Nonetheless, the importance of IL-15 during early infection and autoimmunity is unclear. Furthermore, the mechanisms regulating IL-15 responses in both inflammatory situations and during the steady state are still being elucidated. The mechanisms by which IL-15 mediate responses are unique among cytokines. IL-15 associates with IL-15R $\alpha$ within cells where it can either be transpresented to neighboring cells or cleaved into a soluble cytokine/receptor complex. Increased production of soluble (s)IL-15R $\alpha / \mathrm{IL}-15$ complexes is seen upon different types of immune stimulation, suggesting that these are circumstance when sIL-15 complexes are most likely to act. How common this response is remains unclear, as the production of sIL-15 complexes has only been recently appreciated. This review sets out to emphasize how IL-15 is frequently increased in response to pathogen infections and during autoimmunity and inflammatory conditions. Since pathogen infections and inflammatory diseases share signaling pathways that induce sIL-15 complexes, including pattern recognition receptors and type I interferon, sIL-15 complexes may be generated in more situations than realized. While there are multiple cellular targets of IL-15, this review primarily focuses on how T-cells are likely affected by IL-15 during immune activation and describes evidence for the aforementioned activities. Some of these responses include effects on T-cell proliferation, survival, metabolism, trafficking, and effector functions. Lastly, potential and current therapies that regulate IL-15-mediated responses during infections, autoimmunity, and cancer are discussed. Overall, IL-15 is a not just a factor promoting the differentiation and homeostasis of memory CD8 T-cells, but it is an important immune modulator acting in many circumstances involving immune stimulation and activation.

Keywords: autoimmunity, infection, inflammation, cytokines, pattern recognition receptors, interferons

\section{Introduction}

The importance of interleukin (IL)-15 in promoting the development and homeostasis of a group of lymphocytes is well established, but its roles during T-cell activation and inflammatory responses are less appreciated. This is in spite of the fact that IL-15 expression is often upregulated during immune stimulation, pathogen infections, and numerous other inflammatory situations. Since high quantities of IL-15 can promote T-cell proliferation and enhance T-cell effector responses, ${ }^{1}$ activation-induced IL-15 is likely contributing to enhanced T-cell responses that are concomitantly observed. 
When the association between increased IL-15 expression and immune activation was originally discovered, there was active research in determining the contribution of IL-15 in the inflammatory process; however, challenges in elucidating the mechanisms regulating IL-15 production and the corresponding mode of action led to waning interest in this area. Renewed interests have resurged as novel mechanisms of IL-15 have become elucidated. As such, this review first describes the unique attributes of IL-15 and the potential mechanisms that IL-15 may be utilizing. This is followed by a description of the compelling amount of data showing increased IL-15 during inflammation, including pathogen infections and autoimmunity. The discovery that generation of soluble (s)IL-15 complexes is increasingly being linked to immune activation and inflammation implicates that either sIL-15 complexes are uniquely mediating responses during immune activation, or they are a biomarker for enhanced IL-15 signaling. Hence, this review discusses the various ways IL-15 could impact T-cells during immune activation and inflammation. Unfortunately, due to space constraints, natural killer (NK) cell responses that are likely stimulated in parallel are only minimally discussed herein but are well described in a recent review. ${ }^{2}$ A description of studies utilizing recombinant forms of IL-15 to promote T-cell responses is briefly discussed. Future investigations clarifying the role of IL-15 during immune stimulation and the corresponding mechanism will surely lead to a better understanding of how to either enhance or suppress IL-15 responses for therapeutic purposes.

\section{Mechanisms of action: transpresentation and paracrine signaling}

IL-15 is structurally similar to IL-2 and both cytokines signal through two shared receptor subunits, the IL-2/15 $\beta$ chain (CD122) and the common $\gamma$ chain $(\gamma \mathrm{C})$. IL-15 and IL-2 both have a private $\alpha$ chain, the IL-15R $\alpha$ and IL-2R $\alpha$ (CD25), respectively, that act mostly to confer cytokine specificity, possessing little to no inherent signaling ability. IL-2R $\alpha$ expression is mostly restricted to T-cells, which is upregulated upon T-cell receptor (TCR) stimulation and then converges with the IL-2R $\beta$ and $\gamma \mathrm{C}$ to form a competent IL-2 receptor complex that is stimulated by autocrine-produced IL-2. This receptor complex formation is necessary for IL-2 signaling, as IL-2R $\alpha$ alone has a low affinity for IL-2 $\left(\mathrm{kD} \sim 10^{-8} \mathrm{M}\right)$. In contrast, IL-15R $\alpha$ is expressed by virtually all cells, but its expression by T-cells or NK cells is not necessary for responding to IL-15. IL-15R $\alpha$ alone has a very high affinity for IL-15 $\left(\mathrm{kD} \sim 10^{-11} \mathrm{M}\right)$, which is not further enhanced by the presence of the signaling receptor subunits IL-2R $\beta$ and $\gamma \mathrm{C} .3,4$ Therefore, it was evident early on that IL-15 and IL-2 acted in different manners, but the role of the IL-15R $\alpha$ in mediating IL-15 responses was unclear. This confusion resolved once it was shown that IL-15 and IL-15R $\alpha$ are expressed in the same cell, bound intracellularly and then shuttled to the surface as a complex. ${ }^{5}$ In elegant in vitro experiments, the cell-associated IL-15R $\alpha /$ IL-15 complexes were shown to stimulate adjacent cells through the IL- $2 \mathrm{R} \beta / \gamma \mathrm{C}$ complex during a cell-cell interaction that was called transpresentation. ${ }^{5}$ As such, these studies changed our idea of IL-15 as a soluble factor and opened the doors to further investigate this unique mechanism of cytokine stimulation in trans.

The mechanism of IL-15 transpresentation is ideally suited to limit the availability of a cytokine which, when produced in high levels, induces robust lymphocyte stimulation. ${ }^{1}$ Furthermore, since IL-15 is needed continuously for lymphocyte development and homeostasis, cell delivery of IL-15 allows constitutive availability that is restricted between specific cells types. Nonetheless, other potential mechanisms of IL-15 have been proposed. The Cis model of IL-15 delivery proposes that the flexible nature of the IL-15/IL-15R $\alpha$ complex allows stimulation of the adjacent IL-2R $\beta / \gamma \mathrm{C}$ on the same cell. Alternatively, IL-15R $\alpha$ expressing cells could bind free IL-15, which becomes subsequently Cis-presented; however, whether IL-15 is produced in the absence of IL- $15 \mathrm{R} \alpha$ is questionable. Overall, the mechanism of Cis-presentation is feasible, but evidence that it is utilized in vivo is limited.

A third mechanism mediating IL-15 responses involves the paracrine stimulation of IL- $2 \mathrm{R} \beta / \gamma \mathrm{C}+$ cells by soluble IL-15R $\alpha /$ IL-15 complexes (herein referred to as sIL-15 complexes). sIL-15 complexes can be generated endogenously by cleaving IL-15R $\alpha /$ IL-15 complexes from the cell surface or generated recombinantly, where they have been shown to be 50-100-fold more potent than recombinant (r)IL-15.6,7 Evidence that endogenous sIL-15 complexes mediate responses in vivo is supported by observations that IL-15 responses coincide with the transient appearance of sIL-15 complexes in the serum of mice treated with Poly $\mathrm{I}: \mathrm{C}$, lipopolysaccharide, and certain pathogens. ${ }^{8}$ Additionally, lymphodepletion increases serum sIL-15 complexes in mice and humans. ${ }^{9}$ A major question remains as to whether the endogenous sIL-15 complexes are present in sufficient concentrations to mediate responses above and beyond what transpresentation is accomplishing. If not directly mediating IL-15 responses, the appearance of sIL-15 complexes 
is a potential biomarker for enhanced IL-15 signaling. With the growing number of reports showing that sIL-15 complexes are induced during different types of immune stimulation, ${ }^{8,9,10,11}$ a deeper investigation of the importance of these induced sIL-15 complexes is needed. Regardless of the physiological role of endogenous sIL-15 complexes, rsIL-15 complexes are a promising therapeutic approach for inducing robust IL-15 responses. Overall, paracrine stimulation by sIL-15 complexes is a mechanism capable of mediating responses in vivo.

The study by Bergamaschi et $\mathrm{al}^{9}$ investigating sIL-15 complexes generated upon lymphodepletion went on to further show that all of the soluble IL-15 present is associated with the IL-15R $\alpha$ protein. This finding raises questions of whether free IL-15 is ever present in the physiological state and how to interpret conclusions from previous reports detecting IL-15 protein in biological solutions. ${ }^{12-14}$ In contrast to those reports, other studies have been unable to detect free IL-15, which has been attributed to the sequestering of IL-15 to the cell surface. ${ }^{5}$ These discrepancies could be due to the use of different IL-15 antibodies that, depending on the epitope recognized, are not able to distinguish free IL-15 from sIL-15 complexes. In addition, different methods can yield very different protein values. For example, studies typically report very low levels of IL- 15 protein $(0-15 \mathrm{pg} / \mathrm{mL})$ in control patients, as determined by enzyme-linked immunosorbent assay (ELISA), while other studies report levels in the $200-300 \mathrm{pg} / \mathrm{mL}$ range using Luminex. ${ }^{15}$ What each of these assays (free IL-15 or sIL-15 complexes) is specifically measuring is unclear. Throughout this review, numerous studies reporting increased IL-15 protein are mentioned, but in most circumstances, the form of IL-15 detected has not been identified. Overall, a re-examination of IL-15 protein with more specific and validated assays is warranted to identify the true nature of the IL-15 found.

\section{IL-I 5 cellular targets and sources}

In general, the responsiveness of lymphocytes to IL-15 is associated with their expression level of CD122. Among lymphocytes, memory CD8 T-cells, NK cells, invariant NK T-cells, CD8 $\alpha \alpha$ intestinal intraepithelial lymphocytes (IELs), and TCR $\gamma \delta$ T-cells express the highest levels of CD122 and are the cell types most responsive to IL-15. Naïve CD8 T-cells express a low level of CD122 expression that confers a lower level of sensitively toward sIL-15, which is greater than that of naïve CD4 T-cells but less than that of memory CD8 T-cells or NK cells. Indeed, IL-15 contributes to the maintenance of normal numbers of naïve CD8 T-cells by promoting survival. Upon T-cell activation, CD122 expression is upregulated by both CD4 and CD8 T-cells and maintained throughout the contraction and memory phase; however, the higher expression of CD122 on CD8 T-cells vs CD4 T-cells is still preserved. While murine memory CD8 T-cells are much more sensitive to IL-15 than to naïve CD8 T-cells, human naïve and memory CD8 T-cells have a more similar responsiveness to IL-15. ${ }^{16}$ Although upregulation of CD122 occurs immediately upon T-cell activation, a clear role for IL-15 during these early stages of T-cell activation has not been established; however, there is evidence that IL-15 impacts early T-cell responses, which will be described later. Overall, at each stage of differentiation, CD8 T-cells are responsive to IL-15, albeit at varying levels, and thus are targets of IL-15 produced during immune activation.

IL-15 is crucial for the generation and maintenance of memory CD8 T-cells, which is exemplified by the decreased proportion of memory phenotype CD8 T-cells (CD44hi) present in IL-15 and IL-15R $\alpha-/-$ mice. ${ }^{17,18}$ In response to an acute infection, IL-15 promotes the survival of antigenspecific effector CD8 T-cells during the contraction phase. ${ }^{19,20}$ Once differentiation of antigen-specific memory CD8 T-cells is established, IL-15 drives a continual, but slow level of homeostatic proliferation that contributes to the longevity of memory CD8 T-cells. ${ }^{19,20}$ Despite CD122 being upregulated immediately after T-cell activation, in many cases, the importance of IL-15 does not become apparent until the later stages of CD8 T-cell differentiation. This generation and homeostasis of memory CD8 T-cells was found to be heavily dependent upon macrophages and dendritic cells (DCs) expressing IL-15R $\alpha$, suggesting that these are the major cell types transpresenting IL-15 to memory CD8 T-cells. ${ }^{21,22}$ The reason IL-15 actions are limited to this window of time could be due to changing migration patterns that permit T-cell access to IL-15 transpresenting cells or epigenetic regulation that impacts IL-15 responsiveness. Alternatively, IL-15 may mediate responses other than increased survival and proliferation at earlier stages of the T-cell immune response that have not yet been realized.

Similar to memory CD8 T-cells, IL-15 is critical for the normal development and homeostasis of NK cells, invariant NKT cells, intestinal IELs, and TCR $\gamma \delta$ T-cells. ${ }^{17,18,23}$ In the absence of IL-15, the numbers of these innate lymphocytes is severely decreased. ${ }^{17,18,23}$ Interestingly, for each of these cell types, IL-15 acts locally at the site of lymphocyte development. For instance, IL-15 produced within the bone marrow (BM) promotes NK cell development, while that produced by thymic epithelial cells drives the development of invariant 
NKT cells. ${ }^{24,25}$ Once these cells leave those tissue sites, IL-15 provided by other cellular sources continues to promote their survival. ${ }^{24,25}$ Distinct sources of IL-15 are also found in mucosal tissues where the production of IL-15 by intestinal enterocytes promotes the development of CD $8 \alpha \alpha$ IELs and subsequently supports their survival. ${ }^{26}$ More recent studies have elaborated on our understanding of IL-15 expression in vivo by examining IL-15 reporter mice. ${ }^{27-30}$ These model systems confirm that myeloid cells, particularly CD8+ DCs, are a predominate source of IL-15 and identify expression by cell types that had been suspected to express IL-15 (ie, thymic epithelial cells, bone marrow stromal cells), as well as other unsuspected cell types (ie, endothelial cells, neutrophils). ${ }^{27-30}$ Altogether, IL-15 has a broad tissue distribution that includes a variety of nonhematopoietic and hematopoietic cell types. Whereas these innate lymphocytes are targets for IL-15 during infections and autoimmunity, the remaining portion of this review will focus on how IL-15 impacts T-cells during immune activation.

\section{Regulation of IL- I 5 during pathogen infections}

As mentioned, IL-15 responses are critical during the contraction and memory phase of antigen-specific CD8 T-cell responses and are believed to be mediated by constitutively expressed IL-15 that is delivered via transpresentation. ${ }^{19,20,31,32}$ Nonetheless, IL-15 expression is increased in response to numerous pathogen infections. Since effector T-cells are highly IL-15 responsive, it is very reasonable that IL-15 influences T-cells early in the response. Within this section, we show a compilation of pathogens that increase IL-15 expression (Table 1) and discuss the likely signals leading to this upregulation, with the goal of highlighting the numerous and global stimuli upregulating IL-15 expression.

As one can see in Table 1, a large number of pathogens have been reported to increase IL-15 expression, either at the level of transcript or protein. In some studies, only increases in IL-15 transcripts were reported, which could be due to a lack of available or reliable reagents, failure to examine IL-15 on the cell surface, or an absence in coordinate IL-15 protein expression (Table 1). 1L-15 regulation is primarily posttranscriptional, as multiple mechanisms limit IL-15 protein expression, including negative regulatory elements in the 5'UTR and multiple translational start sites. ${ }^{33-35}$ As such, the significance of increased IL-15 transcripts in the absence of reported increases in IL-15 protein is uncertain. Since transpresentation is a fairly recent concept, examination of cell surface-associated IL-15 has not been typically performed and when attempted, has been challenging. ${ }^{21}$ While there are some reports of increased IL-15 protein in serum or tissue extracts, some of these reported increases, while statistically significant, are marginal. ${ }^{36,37,38}$ In addition, the form of IL-15 protein detected was not always confirmed, as certain ELISAs and multiplex assays have not been validated as to whether these assays specifically detect IL-15 vs sIL-15 complexes. Nonetheless, a few studies, including our own recent observations, have specifically detected increased production of sIL-15 complexes in response to influenza, rhinovirus, and vesicular stomatitis virus (VSV) infection. ${ }^{10,11,39}$ Therefore, pathogen-induced increases in IL-15 could manifest as increased transpresented IL-15 and/or sIL-15 complexes. With the realization of the significance of cell surface IL-15, along with the discovery of sIL-15 complexes, IL-15 expression after pathogen infection is in need of re-evaluation.

The reason many pathogens similarly increase IL-15 is a testament to the numerous and shared pathways able to regulate IL-15, including the activation of pattern recognition receptors (PRRs) and their subsequent induction of additional inflammatory pathways. The PRRs consist of many different types of membrane-bound and cytosolic receptors, each capable of responding to conserved pathogen motifs, termed pathogen-associated molecular patterns or endogenous intracellular molecules that are exposed upon cell damage, called damage associated molecular patterns (DAMPs). ${ }^{40}$ These sensors are highly expressed by antigen-presenting cells and their activation is critical for initiating a robust adaptive immune response. Toll-like receptors (TLRs) are a group of PRRs (TLR1-13) with a common structural motif, homologous to drosophila Toll proteins that stimulate nuclear factor-kappa B (NF- $\mathrm{KB}$ ) and mitogen-activated protein kinase pathways upon ligation by their respective ligands. Early studies demonstrated the strong induction of IL-15 by Poly I:C, lipopolysaccharides, and $\mathrm{CpG}$ that stimulate TLRs 3, 4, and 9 , respectively. ${ }^{41,42}$ Therefore, the biochemical composition of viruses (nucleic acids) and bacteria (lipoglycans, flagellum) are themselves sufficient to induce IL-15 expression through TLR recognition; however, there are multiple mechanisms by which TLR signaling regulates IL-15 expression. The NF- $\kappa \mathrm{B}$ signaling pathway stimulates IL-15 transcription both directly ${ }^{43}$ and indirectly, by inducing type I interferons (IFNs), an additional stimulus of IL-15 reviewed later. TLR ligation also leads to an increase in the generation of sIL-15 complexes, ${ }^{8}$ suggesting that TLR signaling pathways also regulate the cleavage machinery; however, the pathways regulating the generation of sIL-15 complexes have not been 
Table I Reports of increased IL-I5 by various pathogens

\begin{tabular}{|c|c|c|}
\hline Pathogen & Form of IL-I 5 expressed (organism) & References \\
\hline Adeno-associated virus & $\begin{array}{l}\text { Increased mRNA in virus-treated BMDC (mouse); increased cell surface } \\
\text { and soluble protein in GM-CSF-induced DCs (human) }\end{array}$ & 103,104 \\
\hline Bacillus Calmette-Guérin & Increased mRNA in spleen, lung, and liver (mouse) & 36 \\
\hline Candida albicans & Increased mRNA, protein in cultured PBMC (human) & 105 \\
\hline Cytomegalovirus & Increased mRNA in spleen and bone marrow cells (mouse) & 106 \\
\hline Dengue virus & Increased protein in plasma acute infection only (human) & 107 \\
\hline Escherichia coli & Increased mRNA, protein in cultured PBMC (human) & 105 \\
\hline Zaire ebolavirus & $\begin{array}{l}\text { Increased protein in serum by Luminex during end-stage disease in nonsurviving } \\
\text { patients (human) }\end{array}$ & 49 \\
\hline Ebstein-Barr virus & Increased mRNA and IL-I5 biological activity by PBMC (human) & 108 \\
\hline Echinococcus granulosus & Increased mRNA-isolated peritoneal cells (mouse) & 109 \\
\hline Hepatitis $B$ virus & Increased protein in resolving acute infection (human) & 110 \\
\hline Human herpes virus-6 & Increased mRNA, protein in monocytes in vitro (human) & III \\
\hline HIV & $\begin{array}{l}\text { Increased mRNA in DCs of HIV-I infected patients off antiretroviral therapy, } \\
\text { increased protein in serum of nonhuman primates* }\end{array}$ & 37,48 \\
\hline Herpes simplex virus-I & Increased mRNA and protein in PBMC (human) & 112 \\
\hline Human T-lymphotrophic virus-1,2 & Increased mRNA by T-cells (human) & 113 \\
\hline Influenza & Increased mRNA, protein, and sIL-15 complexes in lung lysate and serum (mouse) & 10,114 \\
\hline Leishmania donovani & Increased protein in plasma (human) & 115 \\
\hline Listeria monocytogenes & Increased mRNA, increased IL-I5 biological activity (mouse) & 116 \\
\hline Mycobacterium tuberculosis & $\begin{array}{l}\text { Increased mRNA in infected macrophages in vitro; increased mRNA in lung } \\
\text { with progressive disease using H37Rv strain (mouse) }\end{array}$ & 36,117 \\
\hline Necator americanus (hookworm) & Increased mRNA in duodenal mucosa (human) & 118 \\
\hline Plasmodium falciparum & Increased mRNA in PBMC obtained ex vivo during early disease & 119 \\
\hline Reovirus & Increased mRNA and IL-I5 biological activity by PBMC (human) & 108 \\
\hline Respiratory syncytial virus & $\begin{array}{l}\text { Increased mRNA day I in whole-lung (mouse) mRNA, protein in primary } \\
\text { bronchial epithelial cells (human) }\end{array}$ & $|20| 2 \mid$, \\
\hline Rhinovirus & Increased protein (human) mRNA, protein, slL-I5 complexes (mouse) & 11 \\
\hline Salmonella & $\begin{array}{l}\text { Increased mRNA in infected J774 cells,* increased protein in the serum } \\
\text { of patients with gastroenteritis (human) }\end{array}$ & 38,122 \\
\hline Sendai virus & Increased mRNA, IL-I5 biological activity - PBMC (human) & 108 \\
\hline Staphylococcus aureus & Increased mRNA and protein in PBMC (human) & 105 \\
\hline Toxoplasma gondii & Increased mRNA in macrophages* & 36 \\
\hline Modified vaccinia virus (Ankara strain) & Increased mRNA in infected HeLA cells & 123 \\
\hline Vesicular stomatitis virus & Increased mRNA, protein, sIL-I5 complexes in serum and lung lysate (mouse) & 27,39 \\
\hline
\end{tabular}

Note: *Marginal increase.

Abbreviations: IL, interleukin; mRNA, messenger RNA; BMDC, bone marrow-derived dendritic cell; GM-CSF, granulocyte macrophage colony-stimulating factor; DCs, dendritic cells; PBMC, peripheral blood mononuclear cell; sIL, soluble interleukin.

elucidated. Additionally, many of the pathogens known to induce IL-15 (Table 1) are capable of activating a diverse assortment of PRRs; however, whether PRRs other than TLRs similarly regulate IL-15 is not clear and should be investigated in the future.

Pathogen infections, particularly viruses, often lead to the induction of type I IFNs, which are well-described stimuli of IL-15 expression and responses. ${ }^{41,42}$ Induction of the prototypic type I IFNs, IFN- $\alpha$ and IFN- $\beta$, is a common outcome of signaling through PRRs including TLRs, as well as nucleotide-binding oligomerization domain receptors, RIG-I like receptors, and C-type lectin receptors. ${ }^{40}$ As such, induction of IFNs by these other PRRs may contribute to pathogen-mediated upregulation of IL-15.
Like NF- $\kappa B$, IFN- $\alpha$ directly regulates IL-15 transcription via an IFN-stimulated regulatory element present in the IL-15 promoter. ${ }^{44} \mathrm{At}$ least in VSV, rhinovirus, and influenza infections, type I IFNs have been shown to be crucial in regulating IL-15 transcription, as enhanced transcription was abrogated in IFN- $\alpha / \beta$ receptor (IFNAR)-deficient mice. ${ }^{11,27,45}$ In addition, type I IFN signaling directly leads to enhanced cell surface IL-15 expression, as well as to the generation of sIL-15 complexes. ${ }^{39,46}$ Interestingly, we have found that the production of sIL-15 complexes was not abrogated in VSVinfected IFNAR-/- mice, ${ }^{39}$ indicating that transcription is regulated independently from cleavage of the complexes. Additional viruses, such as lymphocytic choriomeningitis virus and vaccinia virus are known to potently induce type I 
IFNs, ${ }^{47}$ but analyses examining IL-15 expression, surprisingly have not been performed. Nonetheless, these viruses, like many others that induce type I IFNs, are assumed to have coordinate increases in IL-15. Overall, type I IFNs are an important signaling pathway regulating IL-15 expression at multiple levels.

During active acute infections, such as with VSV and rhinovirus, IL-15 expression is only transiently increased. Active rhinovirus infection of mice induces sIL-15 complexes in lung homogenates 24 hours postinfection, which return to baseline 2 days postinfection. ${ }^{11}$ We have observed similar kinetics in VSV-infected mice, where both cell surface IL-15 and serum sIL-15 complexes are increased 24 hours after infection. ${ }^{39}$ Hence, acute pathogen-mediated increases in IL-15 could be impacting T-cells at this very early stage of the T-cell response. Conversely, increased IL-15 can be observed later in chronic infections, which are associated with aberrant immune activation. For example, IL-15 is increased in DCs isolated from the blood of HIV patients after cessation of antiretroviral therapy, when viral loads are increasing. ${ }^{48}$ Additionally, increased IL-15 is observed in end-stage Ebola infection among moribund patients, but not in surviving patients. ${ }^{49}$ Overall, these numerous studies demonstrate that increased $1 \mathrm{~L}-15$ is a common event associated with a wide variety of pathogen infections in mice and humans; however, the role of pathogen-induced increases in IL-15 is not clear.

\section{IL- 5 during autoimmunity and inflammation}

In addition to pathogen infections, IL-15 is increased in various autoimmune diseases and conditions with aberrant immune responses, which are listed in Table 2 and described later. Across these diseases, elevated expression of inflammatory cytokines, such as type I IFNs, tumor necrosis factor (TNF)- $\alpha$, and IL-1, which are capable of increasing IL-15, is a common event that may provide an explanation for the shared effect on IL-15 expression. ${ }^{50}$ In contrast to pathogen infections where increased IL-15 likely has a beneficial role, elevated IL-15 seen in autoimmunity is associated with disease pathogenesis. In addition, since immune activation and inflammation can become chronic in many of these conditions, elevated IL-15 is more likely to persist. As many autoimmune conditions are localized to specific tissues, elevated IL-15 is often observed in those respective tissues; however, increased systemic levels have also been reported (Table 2).

Celiac disease is an inflammatory disorder of the small intestine with characteristics of an autoimmune disease due to an inappropriate immune response to the wheat protein

Table 2 Reports of increased IL-I5 in autoimmunity

\begin{tabular}{|c|c|c|}
\hline Disease/disease model & Form of IL- I 5 expressed & References \\
\hline BD & $\begin{array}{l}\text { Increased protein in aqueous humor and serum samples, higher in serum and cerebral spinal fluid } \\
\text { of remission BD than in active BD (human) }\end{array}$ & 124 \\
\hline Celiac disease & Increased protein on intestinal epithelial cells and in lamina propria cells by IHC and ELISA (human) & 53,54 \\
\hline Crohn's disease & $\begin{array}{l}\text { Increased mRNA macrophages and epithelial cells by in situ hybridization, protein in lamina propria } \\
\text { macrophages by IHC, and mucosal biopsy culture supernatants by ELISA (human) }\end{array}$ & 66,69 \\
\hline Eczema/dermatitis & Increased protein in epidermal keratinocytes and DCs in lesion punch biopsy by IHC (human) & 60,78 \\
\hline Graft-vs-host disease & Increased protein in serum by ELISA (human) & 125 \\
\hline Kawasaki disease & Increased protein in serum during the acute phase, but not during the subacute phase by ELISA (human) & 126 \\
\hline Multiple sclerosis & $\begin{array}{l}\text { Increased mRNA of CNS infiltrating mononuclear cells; increased protein in microglia, macrophages, } \\
\text { and astrocytes from multiple sclerosis lesions by IHC; increased protein in plasma (human) }\end{array}$ & $79,127,128$ \\
\hline Psoriasis & $\begin{array}{l}\text { Increased mRNA and protein expression in primary keratinocytes, dermal and epidermal skin } \\
\text { biopsies (human); increased serum protein (mouse and human) }\end{array}$ & 61,102 \\
\hline Rheumatoid arthritis & Increased protein in synovial macrophages by IHC and synovial fluid by ELISA & 55,56 \\
\hline Sarcoidosis & Increased mRNA and protein in alveolar macrophages (human) & 129 \\
\hline $\begin{array}{l}\text { Systemic lupus erythematosus } \\
\text { Human }\end{array}$ & $\begin{array}{l}\text { Elevated protein in serum in both inactive and active patients; increased cell surface protein } \\
\text { on lesion resident fibroblasts and circulating monocytes (human) }\end{array}$ & $\begin{array}{l}13,15,58 \\
59,60\end{array}$ \\
\hline Mouse model & Increased mRNA in splenocytes and lymph node cells; increased serum protein by ELISA & $|30| 3 \mid$, \\
\hline Thyroiditis & Increased protein in serum by ELISA (human) & 132 \\
\hline Type I diabetes & Increased mRNA in pancreas (human), slight increase in serum protein (human)* & $133-135$ \\
\hline Ulcerative colitis & $\begin{array}{l}\text { Increased mRNA in macrophages and epithelial cells by in situ hybridization, increased protein } \\
\text { in mucosal biopsy culture supernatants in both active and inactive disease, increased serum } \\
\text { protein by ELISA (human) }\end{array}$ & $66,67,69$ \\
\hline
\end{tabular}

Note: *Marginal increases.

Abbreviations: IL, interleukin; BD, Behçet's disease; IHC, immunohistochemistry; ELISA, enzyme-linked immunosorbent assay; mRNA, messenger RNA; DC, dendritic cell; CNS, central nervous system. 
gluten. In genetically susceptible individuals, gluten-specific CD4 T-cells and concomitant antibody responses are generated, leading to expansion and activation of IELs, destruction of enterocytes, and villous atrophy. Numerous studies have confirmed a central role for IL-15 in the pathogenesis of disease. ${ }^{51-54}$ IL-15 protein expression is elevated locally in both the lamina propria and intestinal epithelium where it elicits different effects on disease progression. ${ }^{51-54}$ In the lamina propria, elevated IL-15 promotes inflammatory properties in DCs that discourage differentiation of suppressive regulatory T-cells (Tregs) and boost T-helper 1 differentiation, leading to the loss of oral tolerance. The inflammatory microenvironment induces the upregulation of nonclassical major histocompatibility complex class I molecules, MIC-A and MIC-B, by enterocytes that allow for the recognition and eventual destruction of the enterocytes by activated cytolytic IELs. ${ }^{52}$ In general, celiac disease appears to be a "perfect storm" of how the many different functions of IL-15 in excess can converge to cause disease. How this IL-15 storm initially develops is still not entirely understood, exemplifying the importance of understanding the mechanisms regulating IL-15 and its role on various target cells.

The association with increased IL-15 and localized inflammation is also seen in rheumatoid arthritis (RA), a disease characterized by chronic inflammation of the joints. High levels of IL-15 protein are evident in the synovial fluid of approximately $50 \%$ of RA patients. ${ }^{55}$ Synovial macrophages and fibroblasts produce IL-15, which is thought to play a significant role in the recruitment, enhanced survival, and effector molecule production of CD8 T-cells in RA. ${ }^{56}$ Accordingly, IL-15 expression in the synovial fluid is associated with an increased number of infiltrating T-cells with increased expression of Bcl-2. ${ }^{56}$ Interestingly, the IL-15 protein is elevated more significantly in the serum of longterm disease RA patients $(88-152 \mathrm{pg} / \mathrm{mL})$ in comparison to healthy donors $(0-16 \mathrm{pg} / \mathrm{mL})$, suggesting systemic IL-15 is indicative of more aggressive RA disease activity. ${ }^{55}$

Unlike celiac disease and RA, which involve local inflammation, systemic lupus erythematosus (SLE) is a systemic inflammatory disease involving inappropriate innate and adaptive immune responses resulting in immune complexes of antibodies against self-DNA or nucleoproteins. ${ }^{57}$ The IL-15 protein is elevated in the serum of approximately $40 \%-60 \%$ of SLE patients and these levels strongly correlate with lymphocyte expression of the prosurvival factor, Bcl-2. ${ }^{13,58}$ An additional strong correlation exists between SLE disease activity and the percentage of circulating cytotoxic CD8 T-cells expressing the effector molecules granzyme B and perforin. ${ }^{59}$ SLE patients also have increased cell surface expression of IL-15 by monocytes and skin fibroblasts, as determined by flow cytometry and immunohistochemistry, respectively, indicating that both paracrine and transpresentation of IL-15 may be utilized. ${ }^{58,60}$ Surprisingly, IL-15 is elevated in the serum of SLE patients in both inactive and active patients, irrespective of disease activity. ${ }^{15,58}$ This is in contrast to late-stage RA and psoriasis where the presence of IL-15 is a potential biomarker of disease activity. ${ }^{55,58,61}$ Therefore, while there is a clear link between IL-15 and inflammation, the levels of IL-15 do not always correlate with disease severity.

In addition to autoimmune diseases, other types of aberrant immune activation are associated with increased IL-15, including graft-vs-host disease, allograft rejection, T-cell large granular lymphocyte leukemia, and inflammatory bowel disease (IBD) ${ }^{62-64}$ IBD encompasses two main types of intestinal inflammation, Crohn's disease and ulcerative colitis, both of which are believed to develop as an inappropriate response to commensal bacteria. ${ }^{65}$ IL-15 and IL-15R $\alpha$ are increased in the intestines of patients with IBD, with most reports finding increased levels in ulcerative colitis. ${ }^{66-69} \mathrm{In}$ addition, increased IL-15 extends beyond the intestines, as increased levels of serum IL-15 and numbers of IL-15expressing peripheral blood mononuclear cells of ulcerative colitis patients have also been reported. ${ }^{67}$ Furthermore, the increases in systemic IL-15 correlate with disease activity and decrease upon successful treatment. Using a mouse model for intestinal inflammation, IL-15 was shown to be important for disease progressions as IL-15-deficient mice were more resistant to dextran sodium sulfate-induced intestinal inflammation. ${ }^{70}$ Furthermore, dextran sodium sulfate-treated IL-15-deficient mice had decreased numbers of lamina propria CD44hi CD8 T-cells with a corresponding reduction in inflammatory cytokines. ${ }^{70}$ While increases in IL-15 expression could very well be contributing to the inflammatory process in IBD, how central it is to disease initiation or pathogenesis is unclear.

Inflammation is a common feature among autoimmune diseases and aberrant inflammatory conditions associated with elevated IL-15 expression. The same PRR signaling pathways activated during infections also significantly contribute to the inflammation and presumably to the upregulated IL-15 observed during autoimmunity. ${ }^{40-43}$ In SLE, it is hypothesized that TLR activation in response to self-nucleic acids (ie, endogenous DAMPs) induces type I IFN production and plays a significant role in disease pathogenesis. ${ }^{57}$ Since type I IFN signaling is central to the pathogenesis of 
SLE, enhanced type I IFN signaling is at least one potential mechanism mediating increases in IL-15 expression in SLE. ${ }^{71}$ In IBD, exaggerated immune responses to commensal gutresident bacteria correlates with increased intestinal IL-15 expression and infiltration of activated CD8 T-cells. ${ }^{65}$ Furthermore, the intestinal lining can become compromised in IBD and during HIV infection, which allows commensal bacteria to enter the circulation, exposing the patient to endotoxins that have the ability to further enhance IL-15 expression. Overall, from these studies, it is clear that PRR-induced IL-15 is a prominent pathway dysregulated in autoimmunity and inflammatory diseases that could be contributing to disease pathogenesis.

\section{Potential roles of IL- I 5 during immune activation}

In the prior two sections, we have described the inordinate amount of data linking the upregulation of IL-15 with inflammation exhibited during autoimmunity and pathogen infections. Many of these circumstances are associated with increased T-cell numbers, which could be attributed to the ability of IL-15 to promote T-cell proliferation; however, IL-15 can influence T-cells in other ways. In this section, we describe many of the ways that IL-15 directly alters T-cell functions, which likely potentiate the T-cell activities during these conditions.

Studies investigating the role of IL-15 in immune responses typically focus on the ability of IL-15 to promote T-cell proliferation. In vitro stimulation of memory phenotype CD8 T-cells with IL-15 induces proliferation nearly equivalent to $\alpha$ CD3-mediated TCR stimulation. ${ }^{72}$ Since TCRmediated T-cell expansion is a hallmark of early pathogen infections, it is unclear how much proliferation is influenced by IL-15. In essence, IL-15 may not be required for T-cell expansion in many cases simply because the proliferative response is already at its maximum; however, less robust T-cell responses may be subject to influences by IL-15. For instance, the expansion of VSV-specific CD8 T-cells and lymphocytic choriomeningitis virus-specific CD8 T-cells against minor epitopes are decreased in the absence of IL-15. ${ }^{19,20}$ Altogether, these data suggest that TCR affinity may dictate the importance of IL-15 in facilitating T-cell expansion.

The ability of IL-15 to enhance low-affinity T-cell responses is also pertinent to autoimmunity and antitumor responses, as IL-15 lowers the threshold of T-cell activation. ${ }^{73}$ As such, aberrant levels of IL-15 can permit activation of T-cells that otherwise would have remained tolerant. Indeed, the ability of IL-15 to break tolerance to tumor antigens is evident in numerous models. ${ }^{74-76}$ Moreover, in colorectal cancer patients, increased intestinal IL-15 expression is associated with a local T-cell response that strongly correlates with disease-free survival. ${ }^{77}$ Among many autoimmune diseases, the local or systemic overexpression of IL-15 is associated with increases in CD8 T-cells. For example, elevated CD8 T-cells are observed in the synovial fluid of RA patients, in the skin lesions of eczema patients, in multiple sclerosis lesions, in the pancreatic islets of type I diabetes patients, in the serum of SLE patients, and as previously mentioned, in the intestines of celiac disease and IBD patients. ${ }^{56,66,78-81}$ Clearly, elevated IL-15 is strongly associated with enhanced T-cell numbers in a multitude of autoimmune diseases, providing compelling evidence that IL-15 is not merely a factor increased as a consequence to the inflammatory process, but one that also contributes to the inflammatory response.

IL-15 can impact overall T-cell numbers and the differentiation of memory T-cells by promoting survival and regulating the metabolic activity of CD8 T-cells. IL-15 signaling is well described to promote upregulation of the antiapoptotic proteins, Bcl-2 and Bcl-xL, while simultaneously suppressing the proapoptotic protein, Bax. ${ }^{82-84}$ Evidence that IL-15 promotes T-cell survival via these mechanisms is apparent in some diseases. For instance, Bcl-2 is increased in CD8 T-cells in SLE patients and eczema lesions. ${ }^{13,78}$ IL-15 also has the potential to affect T-cell numbers by regulating metabolic activity. IL-15 signaling acts to maintain the integrity of the mitochondrial membrane, at least partially by tipping the balance of antiapoptotic over proapoptotic protein expression. Stimulating T-cells in the presence of IL-15 preferentially drives increased mitochondrial biogenesis leading to enhanced oxidative phosphorylation over glycolysis, while also enhancing the capacity to uptake extracellular glucose. ${ }^{85}$ Promoting this metabolic pathway (ie, oxidative phosphorylation) maximizes adenosine triphosphate production and allows for enhanced survival in times of stress. Correspondingly, T-cells activated in the presence of IL-15 are more likely to survive in vivo after adoptive transfer and differentiate into memory CD8 T-cells. ${ }^{86}$ Interestingly, IL-2 has the opposite effect of promoting the continued reliance on glycolysis, even though IL-2 and IL-15 utilize the same receptors subunits. ${ }^{86}$ This differential response by IL-15 and IL-2 may indicate that signal duration is an important determinant regulating cell metabolism. Overall, IL-15 utilizes multiple mechanisms to enhance the survival of T-cells, which thus promotes increased T-cell numbers. 
In addition to effects on proliferation and survival, IL-15 can also affect T-cell numbers by influencing T-cell trafficking. In vitro, IL-15 has been shown to upregulate the production of chemokines (MIP1 $\beta$, MIP1 $\alpha$, RANTES) and chemokine receptors, CCR2, CCR4, CCR5, CCR7, CCR8, CCR5, CCR6, CXCR4, and CXCR6 ${ }^{87,88}$ The observed differences in chemokine and chemokine receptors regulated by IL-15 likely depend on the target cell, its stage of differentiation, and the local microenvironment. The migration of CD8 T-cells by IL-15 is also evident in vivo. IL-15 increases O-glycan expression, a T-cell selectin ligand that recognizes $\mathrm{P}$ - and E-selectins expressed on activated endothelial tissue. Recently, memory CD8 T-cells, but not naïve CD8 T-cells, were found to migrate into a plethora of tissues, including the lung, liver, and skin, in response to numerous pathogens. This migration was dependent upon local inflammation and the T-cell expression of core 2-O-glycans, but interestingly it occurred independently of cognate antigen ${ }^{89}$ This antigen-independent recruitment required IL-15 signaling, as the number of adoptively transferred CD8 memory T-cells migrating into the lung in response to inflammation was significantly reduced in IL-15 knockout mice. ${ }^{89}$ IL-15 is also important in trafficking to mucosal tissues, as mice lacking IL-15 expression also had a significant reduction in the percentage of antigen-specific CD8 T-cells in the bronchoalveolar lavage fluid in response to influenza infection. ${ }^{10}$ In addition to the requirement for IL-15 in optimal CD8 T-cell migration, IL-15 alone is also sufficient to induce the migration of CD8 T-cells. ${ }^{10}$ During a mouse model of influenza, the local delivery of recombinant sIL-15 complexes into the airways induced the migration of flu-specific CD8 T-cells into the bronchoalveolar lavage fluid only 12 hours postinjection. ${ }^{10}$ Based on these results, the induction of IL-15 has the potential to play a significant role in the early trafficking of effector and memory CD8 T-cells.

IL-15 also induces effector responses directly in CD8 T-cells and NK cells. ${ }^{8,90}$ rIL-15 stimulation alone upregulates TNF- $\alpha$ expression ${ }^{91}$ and increases the expression of granzyme B in a dose-dependent manner in memory phenotype (CD44hi) CD8 T-cells in vivo. ${ }^{92}$ In addition, IL-15 stimulation alone enhances the protein expression of granzyme $\mathrm{B}$, perforin, IFN $\gamma$, and TNF- $\beta$ in memory phenotype CD8 T-cells. ${ }^{72}$ IL-15 also exerts multiple indirect mechanisms to enhance the effector activity of CD8 T-cells by influencing the maturation of DCs and modulating the activity of Tregs. ${ }^{93,94}$ During an in vitro coculture assay, IL-15 could prevent the inhibitory activity of Tregs on activated human CD4 and CD8 T-cells. ${ }^{95}$ Correspondingly, IL-15 specifically maintained the proliferation and killing activity of antigen-specific effector memory phenotype CD8 T-cells in vitro in the presence of Tregs. ${ }^{96}$ Thus, IL-15 exerts numerous effects on CD8 T-cell effector function, metabolic activity, survival, and trafficking, which could contribute to inflammatory processes.

\section{Prospects for therapy and future perspectives}

Throughout this review, we have provided examples of how IL-15 is often increased in response to immune activation accompanying infections and autoimmunity where it promotes T-cell proliferation and survival and influences migration and effector functions. These diverse functions make IL-15 an attractive therapeutic target for enhancing vaccines and antitumor regimens, and alternatively for inhibiting $\mathrm{T}$-cell responses during autoimmunity and aberrant immune responses. While some vaccine adjuvants induce IL-15, providing additional IL-15 with vaccination or incorporating IL-15 into viral vectors has been shown in numerous settings to enhance the effectiveness of T-cell-targeted vaccines. The ultimate goal of all cancer vaccines and therapeutics is treatment resulting in curative and long-lasting antitumor protection. It is well established that adaptive immune responses are capable of eliminating cancers in vivo. ${ }^{97}$ The recent successes utilizing immunotherapy highlight that even existing unproductive immune responses can be significantly augmented, leading to curative treatment in many animal models and human patients. ${ }^{97}$ Since antitumor responses are often suboptimal, treatment with IL-15 is ideal for stimulating CD8 T-cells and NK cells, the specific immune cells best suited for eliminating tumors. Unfortunately, difficulties in production coupled with the low in vivo half-life of rIL-15 have slowed progress in the field. Since IL-15 stimulation can also be achieved with the more potent and stable sIL-15 complexes, we predict more effective therapeutic responses will be achieved with sIL-15 complexes than with rIL-15. Indeed, rIL-15 and rsIL-15 complexes are presently undergoing clinical trials for various types of cancers. Some adjuvant therapies for cancer being considered, such as type I IFNs, TLR agonists, and lymphodepletion, increase endogenous IL-15, which is likely contributing to the corresponding enhanced antitumor responses.

On the opposite side of the coin, blocking IL-15 can reduce undesired T-cell activation occurring in autoimmunity and other diseases. This can be achieved with antibodies against IL-15 or CD122, or sIL-15R $\alpha$ molecules. The caveat of antibodies targeting CD122 is the blocking of IL-2, which may be undesirable as IL-2 supports Tregs, an important cell type maintaining immune tolerance. Despite 
this caveat, CD122 antibodies have been or are currently undergoing clinical trials for celiac disease and T-cell large granular lymphocyte leukemia with the intention of blocking IL-15 activity. Unfortunately, IL-15-specific antibodies are currently not being investigated in human diseases, even though antibodies neutralizing human IL-15 have been generated. sIL-15R $\alpha$ molecules can also block IL-15 activity in vivo, as demonstrated in mouse models of cardiac rejection, collagen-induced arthritis, psoriasis, and T-cell responses against allogeneic antigens and Toxoplasma gondii..$^{98-102}$ Recombinant sIL-15R $\alpha$ molecules were originally developed to bind up free IL-15 and prevent it from stimulating the IL-2R $\beta / \gamma \mathrm{C}$ receptor complex. ${ }^{98}$ Yet, with the knowledge that coupling of IL-15 to sIL- $15 \mathrm{R} \alpha$ enhances the potency of IL-15, the mechanism by which sIL-15R $\alpha$ molecules inhibit IL-15 responses is not clear. The fact that sIL-15R $\alpha$ molecules are effective in certain cases may be evidence that free IL-15 is in fact present in physiological settings, or it may indicate that sIL-15R $\alpha$ can block signaling induced by cell-surface or soluble IL-15/IL-15R $\alpha$ complexes. Although not well appreciated, empty sIL-15R $\alpha$ proteins are produced in vivo. In one study, serum sIL-15R $\alpha$ levels were shown to negatively correlate with disease severity, suggesting that sIL-15R $\alpha$ competes with and blocks the activity of IL-15. ${ }^{102}$ Hence, enhancing endogenous sIL-15R $\alpha$ may be an alternative approach to blocking IL-15 responses.

\section{Conclusion}

In summary, IL-15 is a dynamic factor contributing to enhanced T-cell responses during early infections, autoimmunity, and immune activation. Unlike most cytokines, increased IL-15 responses are not necessarily restricted to a specific type of immune response or class of pathogen. Rather, upregulation of IL-15 is a global response to immune activation that is induced by multiple pathways, which are still undefined. Throughout this review, we strived to bring about a new appreciation for the ability of IL-15 to impact T-cells during immune activation. This is in addition to its roles later in the immune response, where IL-15 is well known to promote the differentiation and homeostasis of memory CD8 T-cells.

\section{Disclosure}

The authors report no conflicts of interests in this work.

\section{References}

1. Fehniger TA, Suzuki K, Ponnappan A, et al. Fatal leukemia in interleukin 15 transgenic mice follows early expansions in natural killer and memory phenotype CD8+ T cells. J Exp Med. 2001;193(2): 219-231.
2. Huntington ND. NK cell recognition of unconventional ligands. Immunol Cell Biol. 2014;92(3):208-209.

3. Giri JG, Kumaki S, Ahdieh M, et al. Identification and cloning of a novel IL-15 binding protein that is structurally related to the alpha chain of the IL-2 receptor. EMBO J. 1995;14(15):3654-3663.

4. Anderson DM, Kumaki S, Ahdieh M, et al. Functional characterization of the human interleukin-15 receptor alpha chain and close linkage of IL15RA and IL2RA genes. J Biol Chem. 1995;270(50): 29862-29869.

5. Dubois S, Mariner J, Waldmann TA, Tagaya Y. IL-15Ralpha recycles and presents IL-15 In trans to neighboring cells. Immunity. 2002;17(5): 537-547.

6. Stoklasek TA, Schluns KS, Lefrançois L. Combined IL-15/IL-15Ralpha immunotherapy maximizes IL-15 activity in vivo. J Immunol. 2006; 177(9):6072-6080.

7. Rubinstein MP, Kovar M, Purton JF, et al. Converting IL-15 to a superagonist by binding to soluble IL-15R \{alpha\}. Proc Natl Acad Sci US A. 2006;103(24):9166-9171.

8. Mortier E, Woo T, Advincula R, Gozalo S, Ma A. IL-15Ralpha chaperones IL-15 to stable dendritic cell membrane complexes that activate NK cells via trans presentation. $J$ Exp Med. 2008;205(5): $1213-1225$.

9. Bergamaschi C, Bear J, Rosati M, et al. Circulating IL-15 exists as heterodimeric complex with soluble IL-15R $\alpha$ in human and mouse serum. Blood. 2012;120(1):e1-e8.

10. Verbist KC, Cole CJ, Field MB, Klonowski KD. A role for IL-15 in the migration of effector CD8 $\mathrm{T}$ cells to the lung airways following influenza infection. J Immunol. 2011;186(1):174-182.

11. Jayaraman A, Jackson DJ, Message SD, et al. IL-15 complexes induce NK- and T-cell responses independent of type I IFN signaling during rhinovirus infection. Mucosal Immunol. 2014;7(5):1151-1164.

12. Wrzesinski C, Paulos CM, Gattinoni L, et al. Hematopoietic stem cells promote the expansion and function of adoptively transferred antitumor CD8 T cells. J Clin Invest. 2007;117(2):492-501.

13. Aringer M, Stummvoll GH, Steiner G, et al. Serum interleukin-15 is elevated in systemic lupus erythematosus. Rheumatology (Oxford). 2001;40(8):876-881.

14. Machado Diaz AC, Chico Capote A, Arrieta Aguero CA, et al. Proinflammatory soluble interleukin- 15 receptor alpha is increased in rheumatoid arthritis. Arthritis. 2012;2012:943156.

15. Bauer JW, Baechler EC, Petri M, et al. Elevated serum levels of interferon-regulated chemokines are biomarkers for active human systemic lupus erythematosus. PLoS Med. 2006;3(12):e491.

16. Kanegane H, Tosato G. Activation of naive and memory $\mathrm{T}$ cells by interleukin-15. Blood. 1996;88(1):230-235.

17. Kennedy MK, Glaccum M, Brown SN, et al. Reversible defects in natural killer and memory CD8 T cell lineages in interleukin 15-deficient mice. J Exp Med. 2000;191(5):771-780.

18. Lodolce JP, Boone DL, Chai S, et al. IL-15 receptor maintains lymphoid homeostasis by supporting lymphocyte homing and proliferation. Immunity. 1998;9(5):669-676.

19. Schluns KS, Williams K, Ma A, Zheng XX, Lefrançois L. Cutting edge: requirement for IL-15 in the generation of primary and memory antigen-specific CD8 T cells. J Immunol. 2002;168(10): 4827-4831.

20. Becker TC, Wherry EJ, Boone D, et al. Interleukin 15 is required for proliferative renewal of virus-specific memory CD8 T cells. J Exp Med. 2002;195(12):1541-1548.

21. Stonier SW, Ma LJ, Castillo EF, Schluns KS. Dendritic cells drive memory CD8 T-cell homeostasis via IL-15 transpresentation. Blood. 2008;112(12):4546-4554.

22. Mortier E, Advincula R, Kim L, et al. Macrophage- and dendritic-cellderived interleukin-15 receptor alpha supports homeostasis of distinct CD8+ T cell subsets. Immunity. 2009;31(5):811-822.

23. Matsuda JL, Gapin L, Sidobre S, et al. Homeostasis of V alpha $14 \mathrm{i}$ NKT cells. Nat Immunol. 2002;3(10):966-974. 
24. Castillo EF, Stonier SW, Frasca L, Schluns KS. Dendritic cells support the in vivo development and maintenance of NK cells via IL-15 transpresentation. J Immunol. 2009;183(8):4948-4956.

25. Castillo EF, Acero LF, Stonier SW, Zhou D, Schluns KS. Thymic and peripheral microenvironments differentially mediate development and maturation of iNKT cells by IL-15 transpresentation. Blood. 2010;116(14):2494-2503.

26. Ma LJ, Acero LF, Zal T, Schluns KS. Trans-presentation of IL-15 by intestinal epithelial cells drives development of CD8alphaalpha IELs. J Immunol. 2009;183(2):1044-1054.

27. Colpitts SL, Stoklasek TA, Plumlee CR, Obar JJ, Guo C, Lefrançois L. Cutting edge: the role of IFN- $\alpha$ receptor and MyD88 signaling in induction of IL-15 expression in vivo. J Immunol. 2012; 188(6):2483-2487.

28. Colpitts SL, Stonier SW, Stoklasek TA, et al. Transcriptional regulation of IL-15 expression during hematopoiesis. J Immunol. 2013;191(6): 3017-3024.

29. Sosinowski T, White JT, Cross EW, et al. CD $8 \alpha+$ dendritic cell trans presentation of IL-15 to naive CD8+ T cells produces antigeninexperienced $\mathrm{T}$ cells in the periphery with memory phenotype and function. J Immunol. 2013;190(5):1936-1947.

30. Cui G, Hara T, Simmons S, et al. Characterization of the IL-15 niche in primary and secondary lymphoid organs in vivo. Proc Natl Acad Sci U S A. 2014;111(5):1915-1920.

31. Burkett PR, Koka R, Chien M, et al. IL-15R alpha expression on CD8+ T cells is dispensable for T-cell memory. Proc Natl Acad Sci U S A. 2003;100(8):4724-4729.

32. Schluns KS, Klonowski KD, Lefrançois L. Transregulation of memory CD8 T-cell proliferation by IL-15Ralpha+ bone marrow-derived cells Blood. 2004;103(3):988-994.

33. Bamford RN, DeFilippis AP, Azimi N, Kurys G, Waldmann TA. The $5^{\prime}$ untranslated region, signal peptide, and the coding sequence of the carboxyl terminus of IL-15 participate in its multifaceted translational control. J Immunol. 1998;160(9):4418-4426.

34. Bamford RN, Battiata AP, Waldmann TA. IL-15: the role of translational regulation in their expression. J Leukoc Biol. 1996;59(4): 476-480.

35. Nishimura H, Yajima T, Naiki Y, et al. Differential roles of interleukin 15 mRNA isoforms generated by alternative splicing in immune responses in vivo. $J$ Exp Med. 2000;191(1):157-170.

36. Doherty TM, Seder RA, Sher A. Induction and regulation of IL-15 expression in murine macrophages. J Immunol. 1996;156(2):735-741.

37. Stacey AR, Norris PJ, Qin L, et al. Induction of a striking systemic cytokine cascade prior to peak viremia in acute human immunodeficiency virus type 1 infection, in contrast to more modest and delayed responses in acute hepatitis B and C virus infections. J Virol. 2009; 83(8):3719-3733.

38. Nishimura H, Hiromatsu K, Kobayashi N, et al. IL-15 is a novel growth factor for murine gamma delta $\mathrm{T}$ cells induced by Salmonella infection. J Immunol. 1996;156(2):663-669.

39. Anthony SM, Howard, M. Hailemichael Y, Overwijk WW, Schluns KS. Soluble Interleukin-15 complexes are generated in vivo by type I Interferon dependent and independent pathways. PLoS One. Epub 2015.

40. Takeuchi $\mathrm{O}$, Akira S. Pattern recognition receptors and inflammation Cell. 2010;140(6):805-820.

41. Zhang X, Sun S, Hwang I, Tough DF, Sprent J. Potent and selective stimulation of memory-phenotype CD8+ T cells in vivo by IL-15. Immunity. 1998;8(5):591-599.

42. Mattei F, Schiavoni G, Belardelli F, Tough DF. IL-15 is expressed by dendritic cells in response to type I IFN, double-stranded RNA, or lipopolysaccharide and promotes dendritic cell activation. J Immunol. 2001;167(3):1179-1187.

43. Washizu J, Nishimura H, Nakamura N, Nimura Y, Yoshikai Y. The NFkappaB binding site is essential for transcriptional activation of the IL-15 gene. Immunogenetics. 1998;48(1):1-7.
44. Azimi N, Shiramizu KM, Tagaya Y, Mariner J, Waldmann TA. Viral activation of interleukin-15 (IL-15): characterization of a virusinducible element in the IL-15 promoter region. J Virol. 2000;74(16): 7338-7348.

45. Durbin JE, Fernandez-Sesma A, Lee CK, et al. Type I IFN modulates innate and specific antiviral immunity. J Immunol. 2000;164(8): 4220-4228.

46. Sikora AG, Jaffarzad N, Hailemichael Y, et al. IFN-alpha enhances peptide vaccine-induced CD8+ T cell numbers, effector function, and antitumor activity. J Immunol. 2009;182(12):7398-7407.

47. Muller U, Steinhoff U, Reis LF, Hemmi S, Pavlovic J, Zinkernagel RM et al. Functional role of type I and type II interferons in antiviral defense. Science. 1994;264(5167):1918-1921.

48. Bastidas S, Graw F, Smith MZ, Kuster H, Günthard HF, Oxenius A. CD8+ T cells are activated in an antigen-independent manner in HIVinfected individuals. J Immunol. 2014;192(4):1732-1744.

49. Wauquier N, Becquart P, Padilla C, Baize S, Leroy EM. Human fatal zaire ebola virus infection is associated with an aberrant innate immunity and with massive lymphocyte apoptosis. PLoS Negl Trop Dis. 2010; 4(10).

50. Stoeck M, Kromer W, Gekeler V. Induction of IL-15 mRNA and protein in A549 cells by pro-inflammatory cytokines. Immunobiology. 1998;199(1):14-22.

51. Meresse B, Chen Z, Ciszewski C, et al. Coordinated induction by IL15 of a TCR-independent NKG2D signaling pathway converts CTL into lymphokine-activated killer cells in celiac disease. Immunity. 2004;21(3):357-366.

52. Hüe S, Mention JJ, Monteiro RC, et al. A direct role for NKG2D/ MICA interaction in villous atrophy during celiac disease. Immunity. 2004;21(3):367-377.

53. DePaolo RW, Abadie V, Tang F, et al. Co-adjuvant effects of retinoic acid and IL-15 induce inflammatory immunity to dietary antigens. Nature. 2011;471(7337):220-224

54. Mention JJ, Ben Ahmed M, Bègue B, et al. Interleukin 15: a key to disrupted intraepithelial lymphocyte homeostasis and lymphomagenesis in celiac disease. Gastroenterology. 2003;125(3):730-745.

55. Gonzalez-Alvaro I, Ortiz AM, Garcia-Vicuña R, Balsa A, PascualSalcedo D, Laffon A. Increased serum levels of interleukin-15 in rheumatoid arthritis with long- term disease. Clin Exp Rheumatol. 2003; 21(5):639-642.

56. McInnes IB, al-Mughales J, Field M, et al. The role of interleukin-15 in T-cell migration and activation in rheumatoid arthritis. Nat Med. 1996;2(2):175-182.

57. Gilliet M, Cao W, Liu YJ. Plasmacytoid dendritic cells: sensing nucleic acids in viral infection and autoimmune diseases. Nat Rev Immunol. 2008;8(8):594-606.

58. Baranda L, de la Fuente H, Layseca-Espinosa E, et al. IL-15 and IL$15 \mathrm{R}$ in leucocytes from patients with systemic lupus erythematosus. Rheumatology (Oxford). 2005;44(12):1507-1513.

59. Blanco P, Pitard V, Viallard JF, Taupin JL, Pellegrin JL, Moreau JF. Increase in activated CD8+ $\mathrm{T}$ lymphocytes expressing perforin and granzyme B correlates with disease activity in patients with systemic lupus erythematosus. Arthritis Rheum. 2005;52(1):201-211.

60. Rappl G, Kapsokefalou A, Heuser C, et al. Dermal fibroblasts sustain proliferation of activated T cells via membrane-bound interleukin-15 upon long-term stimulation with tumor necrosis factor-alpha. J Invest Dermatol. 2001;116(1):102-109.

61. Bouchaud G, Mortier E, Flamant M, et al. Interleukin-15 and its soluble receptor mediate the response to infliximab in patients with Crohn's disease. Gastroenterology. 2010;138(7):2378-2387.

62. Blaser BW, Roychowdhury S, Kim DJ, et al. Donor-derived IL-15 is critical for acute allogeneic graft-versus-host disease. Blood. 2005; 105(2):894-901.

63. Manfro RC, Roy-Chaudhury P, Zheng XX, et al. Interleukin-15 gene transcripts are present in rejecting islet allografts. Transplant Proc. 1997;29(1-2):1077-1078. 
64. Monti P, Scirpoli M, Maffi P, et al. Islet transplantation in patients with autoimmune diabetes induces homeostatic cytokines that expand autoreactive memory T cells. J Clin Invest. 2008;118(5): 1806-1814.

65. Ogura Y, Bonen DK, Inohara N, et al. A frameshift in NOD2 associated with susceptibility to Crohn's disease. Nature. 2001;411(6837): 603-606.

66. Liu Z, Geboes K, Colpaert S, D’Haens GR, Rutgeerts P, Ceuppens JL. IL-15 is highly expressed in inflammatory bowel disease and regulates local T cell-dependent cytokine production. J Immunol. 2000;164(7): 3608-3615.

67. Kirman I, Nielsen OH. Increased numbers of interleukin-15-expressing cells in active ulcerative colitis. Am J Gastroenterol. 1996;91(9): 1789-1794.

68. Nishiwaki T, Ina K, Goto H, et al. Possible involvement of the interleukin-15 and interleukin-15 receptor system in a heightened state of lamina propria B cell activation and differentiation in patients with inflammatory bowel disease. J Gastroenterol. 2005;40(2):128-136.

69. Sakai T, Kusugami K, Nishimura $\mathrm{H}$, et al. Interleukin 15 activity in the rectal mucosa of inflammatory bowel disease. Gastroenterology. 1998;114(6):1237-1243.

70. Yoshihara K, Yajima T, Kubo C, Yoshikai Y. Role of interleukin 15 in colitis induced by dextran sulphate sodium in mice. Gut. 2006;55(3): 334-341.

71. Banchereau J, Pascual V. Type I interferon in systemic lupus erythematosus and other autoimmune diseases. Immunity. 2006;25(3): 383-392.

72. Liu K, Catalfamo M, Li Y, Henkart PA, Weng NP. IL-15 mimics T cell receptor crosslinking in the induction of cellular proliferation, gene expression, and cytotoxicity in CD8+ memory T cells. Proc Natl Acad Sci U S A. 2002;99(9):6192-6197.

73. Deshpande P, Cavanagh MM, Le Saux S, Singh K, Weyand CM, Goronzy JJ. IL-7- and IL-15-mediated TCR sensitization enables T cell responses to self-antigens. J Immunol. 2013;190(4):1416-1423.

74. Oelert T, Papatriantafyllou M, Pougialis G, Hämmerling GJ, Arnold B, Schüler T. Irradiation and IL-15 promote loss of CD8 T-cell tolerance in response to lymphopenia. Blood. 2010;115(11):2196-2202.

75. Schietinger A, Delrow JJ, Basom RS, Blattman JN, Greenberg PD. Rescued tolerant CD8 $\mathrm{T}$ cells are preprogrammed to reestablish the tolerant state. Science. 2012;335(6069):723-727.

76. Klebanoff CA, Finkelstein SE, Surman DR, et al. IL-15 enhances the in vivo antitumor activity of tumor-reactive CD8+ T cells. Proc Natl Acad Sci U S A. 2004;101(7):1969-1974.

77. Mlecnik B, Bindea G, Angell HK, et al. Functional network pipeline reveals genetic determinants associated with in situ lymphocyte proliferation and survival of cancer patients. Sci Transl Med. 2014;6(228): 228 ra37.

78. Orteu CH, Rustin MH, O'Toole E, et al. The inhibition of cutaneous $\mathrm{T}$ cell apoptosis may prevent resolution of inflammation in atopic eczema. Clin Exp Immunol. 2000;122(2):150-156.

79. Saikali P, Antel JP, Pittet CL, Newcombe J, Arbour N. Contribution of astrocyte-derived IL-15 to CD8 T cell effector functions in multiple sclerosis. J Immunol. 2010;185(10):5693-5703.

80. Coppieters KT, Dotta F, Amirian N, et al. Demonstration of isletautoreactive CD8 T cells in insulitic lesions from recent onset and long-term type 1 diabetes patients. $J$ Exp Med. 2012;209(1):51-60.

81. Mazzarella G, Stefanile R, Camarca A, et al. Gliadin activates HLA class I-restricted CD8+ T cells in celiac disease intestinal mucosa and induces the enterocyte apoptosis. Gastroenterology. 2008;134(4):1017-1027.

82. Berard M, Brandt K, Bulfone-Paus S, Tough DF. IL-15 promotes the survival of naive and memory phenotype CD8+ T cells. J Immunol. 2003;170(10):5018-5026.

83. Wu TS, Lee JM, Lai YG, et al. Reduced expression of Bcl-2 in CD8+ T cells deficient in the IL-15 receptor alpha-chain. J Immunol. 2002;168(2):705-712.
84. Oh S, Perera LP, Terabe M, Ni L, Waldmann TA, Berzofsky JA. IL-15 as a mediator of CD4+ help for CD8+ $\mathrm{T}$ cell longevity and avoidance of TRAIL-mediated apoptosis. Proc Natl Acad Sci U SA. 2008;105(13): 5201-5206.

85. van der Windt GJ, Everts B, Chang CH, et al. Mitochondrial respiratory capacity is a critical regulator of $\mathrm{CD} 8+\mathrm{T}$ cell memory development. Immunity. 2012;36(1):68-78.

86. O'Sullivan D, van der Windt GJ, Huang SC, et al. Memory CD8(+) $\mathrm{T}$ cells use cell-intrinsic lipolysis to support the metabolic programming necessary for development. Immunity. 2014;41(1):75-88.

87. Perera LP, Goldman CK, Waldmann TA. IL-15 induces the expression of chemokines and their receptors in T lymphocytes. J Immunol. 1999; 162(5):2606-2612.

88. Unutmaz D, Xiang W, Sunshine MJ, Campbell J, Butcher E, Littman DR. The primate lentiviral receptor Bonzo/STRL33 is coordinately regulated with CCR5 and its expression pattern is conserved between human and mouse. J Immunol. 2000;165(6):3284-3292.

89. Nolz JC, Harty JT. IL-15 regulates memory CD8+ T cell O-glycan synthesis and affects trafficking. J Clin Invest. 2014;124(3):1013-1026.

90. Niedbala W, Wei X, Liew FY. IL-15 induces type 1 and type 2 $\mathrm{CD} 4+$ and $\mathrm{CD} 8+\mathrm{T}$ cells proliferation but is unable to drive cytokine production in the absence of TCR activation or IL-12/IL-4 stimulation in vitro. Eur J Immunol. 2002;32(2):341-347.

91. McInnes IB, Leung BP, Sturrock RD, Field M, Liew FY. Interleukin-15 mediates $\mathrm{T}$ cell-dependent regulation of tumor necrosis factor-alpha production in rheumatoid arthritis. Nat Med. 1997;3(2):189-195.

92. Yajima T, Nishimura H, Sad S, Shen H, Kuwano H, Yoshikai Y. A novel role of IL-15 in early activation of memory CD8+ CTL after reinfection. J Immunol. 2005;174(6):3590-3597.

93. Mohamadzadeh M, Berard F, Essert G, et al. Interleukin 15 skews monocyte differentiation into dendritic cells with features of Langerhans cells. J Exp Med. 2001;194(7):1013-1020.

94. Shevach EM. Mechanisms of foxp3+ T regulatory cell-mediated suppression. Immunity. 2009;30(5):636-345.

95. Ben Ahmed M, Belhadj Hmida N, Moes N, et al. IL-15 renders conventional lymphocytes resistant to suppressive functions of regulatory T cells through activation of the phosphatidylinositol 3-kinase pathway. J Immunol. 2009;182(11):6763-6770.

96. Perna SK, De Angelis B, Pagliara D, et al. Interleukin 15 provides relief to CTLs from regulatory T cell-mediated inhibition: implications for adoptive T cell-based therapies for lymphoma. Clin Cancer Res. 2013;19(1):106-117.

97. Page DB, Postow MA, Callahan MK, Allison JP, Wolchok JD. Immune modulation in cancer with antibodies. Annu Rev Med. 2014;65: 185-202.

98. Smith XG, Bolton EM, Ruchatz H, Wei X, Liew FY, Bradley JA. Selective blockade of IL-15 by soluble IL-15 receptor alpha-chain enhances cardiac allograft survival. J Immunol. 2000;165(6): 3444-3450.

99. Wei Xq, Orchardson M, Gracie JA, et al. The Sushi domain of soluble IL-15 receptor alpha is essential for binding IL-15 and inhibiting inflammatory and allogenic responses in vitro and in vivo. J Immunol. 2001;167(1):277-282.

100. Ruchatz H, Leung BP, Wei XQ, McInnes IB, Liew FY. Soluble IL-15 receptor alpha-chain administration prevents murine collageninduced arthritis: a role for IL-15 in development of antigen-induced immunopathology. J Immunol. 1998;160(11):5654-5660.

101. Khan IA, Moretto M, Wei XQ, Williams M, Schwartzman JD, Liew FY. Treatment with soluble interleukin-15Ralpha exacerbates intracellular parasitic infection by blocking the development of memory CD8+ T cell response. J Exp Med. 2002;195(11):1463-1470.

102. Bouchaud G, Gehrke S, Krieg C, et al. Epidermal IL-15R $\alpha$ acts as an endogenous antagonist of psoriasiform inflammation in mouse and man. $J$ Exp Med. 2013;210(10):2105-2117.

103. Morelli AE, Larregina AT, Ganster RW, et al. Recombinant adenovirus induces maturation of dendritic cells via an NF-kappaB-dependent pathway. J Virol. 2000;74(20):9617-9628. 
104. Vujanovic L, Szymkowski DE, Alber S, Watkins SC, Vujanovic NL, Butterfield LH. Virally infected and matured human dendritic cells activate natural killer cells via cooperative activity of plasma membrane-bound TNF and IL-15. Blood. 2010;116(4):575-583.

105. Tran P, Ahmad R, Xu J, Ahmad A, Menezes J. Host's innate immune response to fungal and bacterial agents in vitro: up-regulation of interleukin-15 gene expression resulting in enhanced natural killer cell activity. Immunology. 2003;109(2):263-270.

106. Nguyen KB, Salazar-Mather TP, Dalod MY, et al. Coordinated and distinct roles for IFN-alpha beta, IL-12, and IL-15 regulation of NK cell responses to viral infection. J Immunol. 2002;169(8): 4279-4287.

107. Azeredo EL, De Oliveira-Pinto LM, Zagne SM, Cerqueira DI, Nogueira RM, Kubelka CF. NK cells, displaying early activation, cytotoxicity and adhesion molecules, are associated with mild dengue disease. Clin Exp Immunol. 2006;143(2):345-356.

108. Fawaz LM, Sharif-Askari E, Menezes J. Up-regulation of NK cytotoxic activity via IL-15 induction by different viruses: a comparative study. J Immunol. 1999;163(8):4473-4480.

109. Mourglia-Ettlin G, Marqués JM, Chabalgoity JA, Dematteis S. Early peritoneal immune response during Echinococcus granulosus establishment displays a biphasic behavior. PLoS Negl Trop Dis. 2011;5(8):e1293.

110. Dunn C, Peppa D, Khanna P, et al. Temporal analysis of early immune responses in patients with acute hepatitis B virus infection. Gastroenterology. 2009;137(4):1289-1300.

111. Flamand L, Stefanescu I, Menezes J. Human herpesvirus-6 enhances natural killer cell cytotoxicity via IL-15. J Clin Invest. 1996;97(6): 1373-1381.

112. Ahmad A, Sharif-Askari E, Fawaz L, Menezes J. Innate immune response of the human host to exposure with herpes simplex virus type 1: in vitro control of the virus infection by enhanced natural killer activity via interleukin-15 induction. $J$ Virol. 2000;74(16): 7196-7203.

113. Azimi N, Brown K, Bamford RN, Tagaya Y, Siebenlist U, Waldmann TA Human $\mathrm{T}$ cell lymphotropic virus type I Tax protein trans-activates interleukin 15 gene transcription through an NF-kappaB site. Proc Natl Acad Sci U S A. 1998;95(5):2452-2457.

114. McGill J, Van Rooijen N, Legge KL. IL-15 trans-presentation by pulmonary dendritic cells promotes effector CD8 T cell survival during influenza virus infection. $J$ Exp Med. 2010;207(3):521-534.

115. Hailu A, van der Poll T, Berhe N, Kager PA. Elevated plasma levels of interferon (IFN)-gamma, IFN-gamma inducing cytokines, and IFNgamma inducible CXC chemokines in visceral leishmaniasis. Am J Trop Med Hyg. 2004;71(5):561-567.

116. Mitani A, Nishimura $\mathrm{H}$, Hirose $\mathrm{K}$, et al. Interleukin-15 production at the early stage after oral infection with Listeria monocytogenes in mice. Immunology. 1999;97(1):92-99.

117. Abebe F, Mustafa T, Nerland AH, Bjune GA. Cytokine profile during latent and slowly progressive primary tuberculosis: a possible role for interleukin-15 in mediating clinical disease. Clin Exp Immunol. 2006;143(1):180-192.

118. Gaze S, McSorley HJ, Daveson J, et al. Characterising the mucosal and systemic immune responses to experimental human hookworm infection. PLoS Pathog. 2012;8(2):e1002520.
119. Hu WC. Human immune responses to Plasmodium falciparum infection: molecular evidence for a suboptimal TH $\alpha \beta$ and $\mathrm{TH} 17$ bias over ideal and effective traditional TH1 immune response. Malar $J$. 2013;12:392.

120. Zdrenghea MT, Telcian AG, Laza-Stanca V, et al. RSV infection modulates IL-15 production and MICA levels in respiratory epithelial cells. Eur Respir J. 2012;39(3):712-720.

121. Estripeaut D, Torres JP, Somers CS, et al. Respiratory syncytial virus persistence in the lungs correlates with airway hyperreactivity in the mouse model. J Infect Dis. 2008;198(10):1435-1443.

122. Mizuno Y, Takada H, Nomura A, et al. Th1 and Th1-inducing cytokines in Salmonella infection. Clin Exp Immunol. 2003;131(1): 111-117.

123. Guerra S, López-Fernández LA, Conde R, Pascual-Montano A, Harshman K, Esteban M. Microarray analysis reveals characteristic changes of host cell gene expression in response to attenuated modified vaccinia virus Ankara infection of human HeLa cells. JVirol. 2004;78(11):5820-5834.

124. Choe JY, Lee H, Kim SG, Kim MJ, Park SH, Kim SK. The distinct expressions of interleukin- 15 and interleukin- 15 receptor $\alpha$ in Behçet's disease. Rheumatol Int. 2013;33(8):2109-2115.

125. Matsuoka K, Koreth J, Kim HT, et al. Low-dose interleukin-2 therapy restores regulatory $\mathrm{T}$ cell homeostasis in patients with chronic graftversus-host disease. Sci Transl Med. 2013;5(179):179ra43.

126. Jang GC, Kim HY, Ahn SY, Kim DS. Raised serum interleukin 15 levels in Kawasaki disease. Ann Rheum Dis. 2003;62(3):264-266.

127. Kivisäkk P, Matusevicius D, He B, Söderström M, Fredrikson S, Link H. IL-15 mRNA expression is up-regulated in blood and cerebrospinal fluid mononuclear cells in multiple sclerosis (MS). Clin Exp Immunol. 1998;111(1):193-197.

128. Liu GZ, Fang LB, Hjelmström P, Gao XG. Increased CD8+ central memory T cells in patients with multiple sclerosis. Mult Scler. 2007; 13(2):149-155.

129. Agostini C, Trentin L, Facco M, et al. Role of IL-15, IL-2, and their receptors in the development of $\mathrm{T}$ cell alveolitis in pulmonary sarcoidosis. J Immunol. 1996;157(2):910-918.

130. Ma N, Xing C, Xiao H, et al. BAFF suppresses IL-15 expression in B cells. J Immunol. 2014;192(9):4192-4201.

131. Ma N, Xiao H, Marrero B, et al. Combination of TACI-IgG and antiIL-15 treats murine lupus by reducing mature and memory B cells. Cell Immunol. 2014;289(1-2):140-144.

132. Figueroa-Vega N, Alfonso-Pérez M, Benedicto I, Sánchez-Madrid F, González-Amaro R, Marazuela M. Increased circulating proinflammatory cytokines and Th17 lymphocytes in Hashimoto's thyroiditis. J Clin Endocrinol Metab. 2010;95(2):953-962.

133. Chen J, Feigenbaum L, Awasthi P, et al. Insulin-dependent diabetes induced by pancreatic beta cell expression of IL-15 and IL-15R $\alpha$. Proc Natl Acad Sci U S A. 2013;110(33):13534-13539.

134. Kuczyński S, Winiarska H, Abramczyk M, Szczawińska K, WieruszWysocka B, Dworacka M. IL-15 is elevated in serum patients with type 1 diabetes mellitus. Diabetes Res Clin Pract. 2005;69(3): 231-236.

135. Monti P, Scirpoli M, Rigamonti A, et al. Evidence for in vivo primed and expanded autoreactive $T$ cells as a specific feature of patients with type 1 diabetes. J Immunol. 2007;179(9):5785-5792.

Research and Reports in Biology

\section{Publish your work in this journal}

Research and Reports in Biology is an international, peer-reviewed, open access journal publishing original research, reports, editorials, reviews and commentaries on all areas of biology including animal biology, biochemical biology, cell biology, ecological studies, evolutionary biology, molecular biology, plant science and botany. The

manuscript management system is completely online and includes a very quick and fair peer-review system. Visit http://www.dovepress. $\mathrm{com} /$ testimonials.php to read real quotes from published authors. 